\title{
Magnetic Field Analysis for Levitation of an Iron Ball in Midair
}

\author{
Y. Ishii, Y. Sugihara, K. Yoshi, and T. Morita \\ Hakodate National College of Technology, Tokura 14-1, Hakodate 042-8501, J apan
}

Sasaki et al. observed an iron ball suspended in midair bel ow five iron balls, in a plastic box attracted by a permanent magnet [J . Appl. Phys. 95, No.4, 2090 (2004)]. The magnetic field exerted by the permanent magnet and five iron balls is analyzed theoretically and experimentally. The position of the suspended iron ball is also calculated from the field, and the results agree well with experimental findings. Without a plastic box, however, an iron ball is found to move away along the magnet ring axis, which is consistent with Earnshaw's theorem.

Key words: magnetic field analysis, magnetic levitation, magnetic force, Earnshaw's theorem

\section{永久磁石による鉄球浮上に関する磁界解析}

石井 良博 · 杉原 裕樹 · 吉一仁・森田孝

函館工業高等専門学校，函館市戸倉町 14-1 ( ₹ 042- 8501)

1. はじめに

Sasaki ら ${ }^{1)}$ は 2004 年, 永久磁石と永久磁石の引力によ ってプラスチック・ケースの天井に吸着した 5 個の鉄球に より，1個の鉄球を空中に安定に浮上させたとの実験結果 を報告している。静磁界だけで強磁性体が安定に浮上する ことはEarnshaw の定理 ${ }^{2)}$ によって不可能とされているが, 彼等は磁界の測定や解析を行ってはいない.

本研究ではSasaki らの浮上実験を再現し, 永久磁石と吸 着鉄球による磁界を理論と実験によって解析し, 浮上鉄球 に働く力を計算することにより, その鉄球が浮上すること を理論的にも確認する。ささらに Earnshawの定理に照ら して, 安定浮上の矛盾について調べる.

この現象は, 密閉容器内の磁性体をごく微小な制御力に よって空中に安定させて移動させたり, 吸着ガスによる質 量の変化の測定などに応用できる可能性がある.

\section{2. 磁界および浮上鉄球に作用する力の計算と測定}

\section{1 リング型のネオジウム磁石による磁界}

リング型のネオジウム磁石と鉄球を Fig. 1 のように配置 した場合の磁界を解析する。ただし，リング磁石は - Z 方向 に磁化しているとする。 また, 図の中の数字は $\mathrm{mm}$ を単位 とする寸法を表している。

最初に, リング磁石による磁束密度を計算するために, リング磁石のみによる磁位 $\varphi_{\mathrm{m}}$ を計算する。リング磁石の 内半径と外半径および厚さをそれぞれ $a, b, 2 d$ とし, 表面 の磁極密度は一定で $\sigma_{\mathrm{m}}$ とする. $\mathrm{z}$ 軸と平行な側面には磁極 が現れないと仮定する. 座標 $\mathrm{z}$ と 軸からの距離が $r$ で表 されるP点の $\varphi_{m}$ は次式で表される ${ }^{3)}$.

$$
\varphi_{\mathrm{m}}=\frac{\sigma_{\mathrm{m}}}{4 \pi \mu_{0}} \int_{\mathrm{a}}^{\mathrm{b}} \int_{0}^{2 \pi}\left(\frac{1}{\mathrm{I}_{1}}-\frac{1}{\mathrm{I}_{2}}\right) \mathrm{r}_{0} \mathrm{~d} \phi \mathrm{dr}_{0},
$$

ただし, $\mu_{0}$ は真空の透磁率, $I_{1}, I_{2}$ はそれぞれ, 磁石の表と 裏の面における， $\left(\mathrm{r}_{0}, \phi\right)$ で表される位置と $\mathrm{P}$ 点の間の距離 で，次式で表される。

$$
\begin{aligned}
& \mathrm{I}_{1}=\sqrt{\mathrm{r}^{2}+\mathrm{r}_{0}^{2}-2 r r_{0} \cos \phi+(z-d)^{2}}, \\
& \mathrm{I}_{2}=\sqrt{\mathrm{r}^{2}+r_{0}^{2}-2 r r_{0} \cos \phi+(z+d)^{2}} .
\end{aligned}
$$

(2)式を(1)式に代入して， $\phi$ についての積分を実行すると， $\varphi_{\mathrm{m}}$ は次式となる.

$$
\begin{gathered}
\varphi_{\mathrm{m}}=\frac{\sigma_{\mathrm{m}}}{\pi \mu_{0}} \int_{\mathrm{a}}^{\mathrm{b}}\left\{\frac{1}{\sqrt{\left(\mathrm{r}+\mathrm{r}_{0}\right)^{2}+(\mathrm{z}-\mathrm{d})^{2}}} \mathrm{~K}\left(\sqrt{\frac{4 r r_{0}}{\left(\mathrm{r}+\mathrm{r}_{0}\right)^{2}+(\mathrm{z}-\mathrm{d})^{2}}}\right)\right. \\
\left.-\frac{1}{\sqrt{\left(\mathrm{r}+\mathrm{r}_{0}\right)^{2}+(\mathrm{z}+\mathrm{d})^{2}}} \mathrm{~K}\left(\sqrt{\frac{4 r r_{0}}{\left(\mathrm{r}+\mathrm{r}_{0}\right)^{2}+(\mathrm{z}+\mathrm{d})^{2}}}\right)\right\} r_{0} \mathrm{dr} r_{0},
\end{gathered}
$$

ここで，K(k)は第一種完全棈円積分関数である.

磁束密度 $\mathrm{B}$ は $\varphi_{\mathrm{m}}$ から次のように得られる.

$$
\mathrm{B}=-\mu_{0} \nabla \varphi_{\mathrm{m}} .
$$

対称性から， x 軸上における磁束密度 B は $\mathrm{z}$ 成分のみを有 する. (4)式を用いて, 磁束密度の $\mathrm{z}$ 成分 $\mathrm{B}_{\mathrm{z}}$ は次式で表され る.

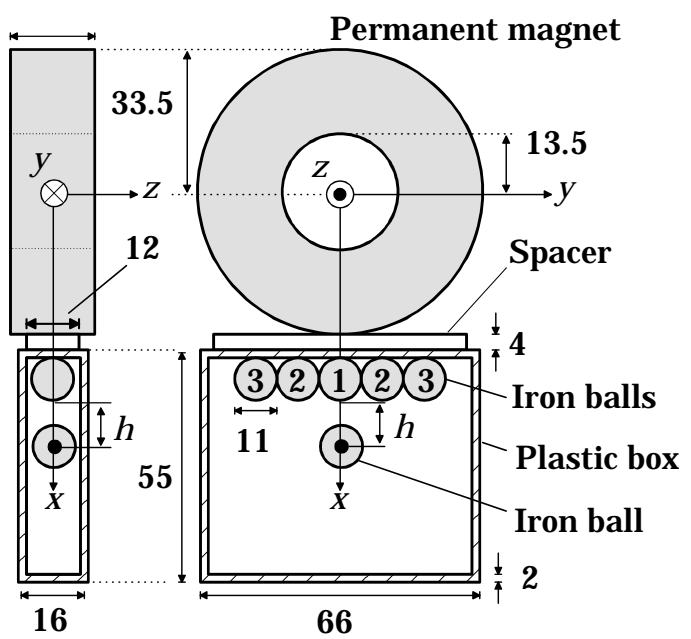

Fig. 1 Schematic illustration of a magnet and iron balls system. 


$$
\begin{aligned}
& \mathrm{B}_{\mathrm{z}}=-\mu_{0}\left(\frac{\partial \varphi_{\mathrm{m}}}{\partial \mathrm{z}}\right)=\frac{\sigma_{\mathrm{m}}}{\pi} \int_{\mathrm{a}}^{\mathrm{b}}\left(\left[\frac{\mathrm{z}-\mathrm{d}}{\left\{\left(\mathrm{r}+\mathrm{r}_{0}\right)^{2}+(\mathrm{z}-\mathrm{d})^{2}\right\}^{3 / 2}}\right.\right. \\
& \times K\left(\sqrt{\frac{4 r r_{0}}{\left(r+r_{0}\right)^{2}+(z-d)^{2}}}\right)+\frac{4 r r_{0}(z-d)}{\left\{\left(r+r_{0}\right)^{2}+(z-d)^{2}\right\}^{5 / 2}} \\
& \times\left\{E\left(\sqrt{\frac{4 r r_{0}}{\left(r+r_{0}\right)^{2}+(z-d)^{2}}}\right) / x_{1}\left(1-x_{1}\right)\right. \\
& \left.\left.-K\left(\sqrt{\frac{4 r r_{0}}{\left(r+r_{0}\right)^{2}+(z-d)^{2}}}\right) / x_{1}\right\}\right]- \\
& {\left[\frac{z+d}{\left\{\left(r+r_{0}\right)^{2}+(z+d)^{2}\right\}^{3 / 2}} K\left(\sqrt{\frac{4 r r_{0}}{\left(r+r_{0}\right)^{2}+(z+d)^{2}}}\right)\right.} \\
& +\frac{4 r r_{0}(z+d)}{\left\{\left(r+r_{0}\right)^{2}+(z+d)^{2}\right\}^{15 / 2}}\left\{E\left(\sqrt{\frac{4 r r_{0}}{\left(r+r_{0}\right)^{2}+(z+d)^{2}}}\right)\right. \\
& \left.\left./ x_{2}\left(1-x_{2}\right)-K\left(\sqrt{\frac{4 r r_{0}}{\left(r+r_{0}\right)^{2}+(z+d)^{2}}}\right) / x_{2}\right\}\right] r_{0} d r_{0} \text {. }
\end{aligned}
$$

(5)式を用いて計算した磁束密度の $\mathrm{z}$ 成分 $\mathrm{B}_{\mathrm{z}}$ が, 吸着鉄球の 表面からの $\mathrm{x}$ 軸上の位置までの距離 $\mathrm{h}$ によって変化する様 子を Fig. 2 に曲線で示す.リング型永久磁石のみによる磁 界は, 磁石から離れるにしたがって, 単調に減少している。 また同図に測定結果を黒丸で示す， $\sigma_{\mathrm{m}}$ を公称值からわずか に調整し， $\sigma_{\mathrm{m}}=1.17 \mathrm{~Wb} / \mathrm{m}^{2}$ とすることによって, 計算結果 を測定結果に合わせるようにしたが，Fig. 2 に示す範囲全 体で両者が非常によく一致していることがわかる.

\section{2 吸着鉄球による磁界}

次にケースの天井に吸着している5個の鉄球による磁界 を計算する。吸着している鉄球は一様に磁化していると仮 定することにより, i 番目の鉄球が作る磁界は鉄球の中心に

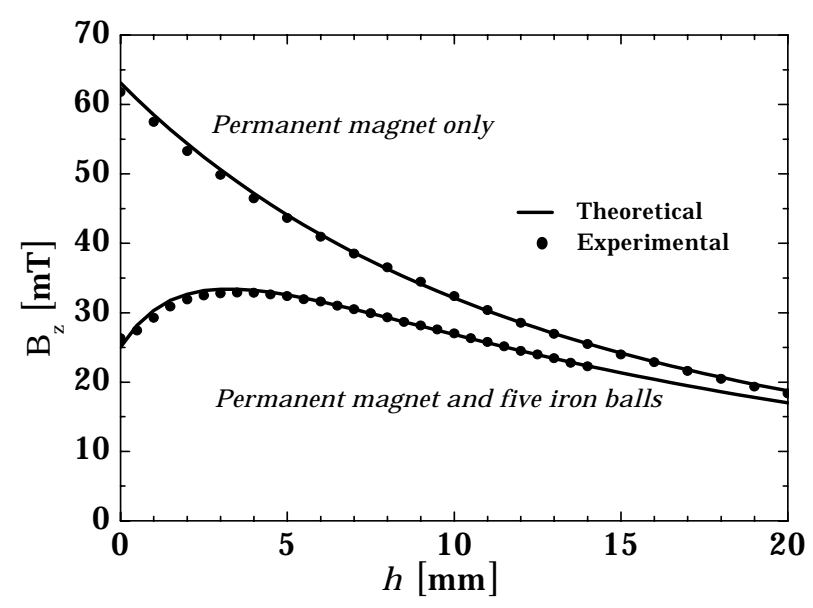

Fig. 2 Flux density $B_{z}$ as a function of $h$. The upper curve shows $B_{z}$ due to the permanent magnet only, and the lower curve shows $B_{z}$ due to the permanent magnet and five iron balls.
位置する双極子モーメントJ $\mathrm{V} V$ による磁界として計算する ことができる.ただし, Jiは i 番目の鉄球の磁化, $\mathrm{V}=\pi \mathrm{D}^{3} / 6$ 拉よび D は鉄球の体積と直径である. 対称性を利用して, 中心から 1, 2, 3 番目の球の磁化は，それぞれ次式で表され る.

$$
\begin{aligned}
& \mathrm{J}_{1}=\chi\left\{\mathrm{H}_{1}-\frac{\mathrm{NJ}}{\mu_{0}}-2 \times \frac{\mathrm{J}_{2} \mathrm{~V}}{4 \pi \mu_{0} \mathrm{D}^{3}}-2 \times \frac{\mathrm{J}_{3} \mathrm{~V}}{4 \pi \mu_{0}(2 \mathrm{D})^{3}}\right\}, \\
& \mathrm{J}_{2}=\chi\left\{\mathrm{H}_{2}-\frac{\mathrm{NJ}_{2}}{\mu_{0}}-\frac{\mathrm{J}_{1} \mathrm{~V}}{4 \pi \mu_{0} \mathrm{D}^{3}}-\frac{\mathrm{J}_{3} \mathrm{~V}}{4 \pi \mu_{0} \mathrm{D}^{3}}-\frac{\mathrm{J}_{2} \mathrm{~V}}{4 \pi \mu_{0}(2 \mathrm{D})^{3}}-\frac{\mathrm{J}_{3} \mathrm{~V}}{4 \pi \mu_{0}(3 \mathrm{D})^{3}}\right\}, \\
& \mathrm{J}_{3}=\chi\left\{\mathrm{H}_{3}-\frac{\mathrm{N} J_{3}}{\mu_{0}}-\frac{\mathrm{J}_{2} \mathrm{~V}}{4 \pi \mu_{0} \mathrm{D}^{3}}-\frac{\mathrm{J}_{1} \mathrm{~V}}{4 \pi \mu_{0}(2 \mathrm{D})^{3}}-\frac{\mathrm{J}_{2} \mathrm{~V}}{4 \pi \mu_{0}(3 \mathrm{D})^{3}}-\frac{\mathrm{J}_{3} \mathrm{~V}}{4 \pi \mu_{0}(4 \mathrm{D})^{3}}\right\},
\end{aligned}
$$

ただし， $\chi$ は鉄球の磁化率であり, 括弧の中は鉄球の内部 の磁界を表している，すなわち $\mathrm{H}_{\mathrm{i}}$ はリング磁石による $\mathrm{i}$ 番 目の鉄球の中心の位置の磁界, 2 項目は反磁界で $N=1 / 3$ は 球の反磁界係数, 3 項目以降は他の鉄球による磁界で, そ の球の中心に置いた磁気双極子による磁界と同じである.

(6)式を連立方程式として解くことにより」が得られる。

吸着鉄球による磁束密度をリング磁石による磁束密度と 加え合わせた計算結果を測定結果とともに，Fig. 2 に曲線 と黒丸で，それぞれ示す， $\chi_{\mathrm{r}}=\chi 1 \mu_{0}=6.76$ としたことに よって, 計算結果は測定結果と非常によく一致した。リン グ磁石と鉄球による磁束密度は $\mathrm{h}=3 \mathrm{~mm}$ の付近にピーク を有し，この辺りで鉄球を浮上させる可能性を示している.

\section{3 浮 上鉄球に作用する力}

Fig. 2 に示した磁界の計算結果を用いて, 次式により浮 上鉄球に作用する力を計算した.

$$
\mathrm{F}=2\left(1-\frac{\mathrm{N}}{2} \frac{\chi_{\mathrm{r}}}{1+\mathrm{N} \chi_{\mathrm{r}}}\right) \frac{\mu_{0} \chi_{\mathrm{r}} \mathrm{V}}{1+\mathrm{N} \chi_{\mathrm{r}}} \mathrm{H} \frac{\partial \mathrm{H}}{\partial \mathrm{x}}
$$

ここで $\mathrm{H}=\mathrm{B}_{\mathrm{z}} / \mu_{0}$ は, 浮上鉄球の中心の位置における Fig. 2 に示した磁界である. (7)式の導出については

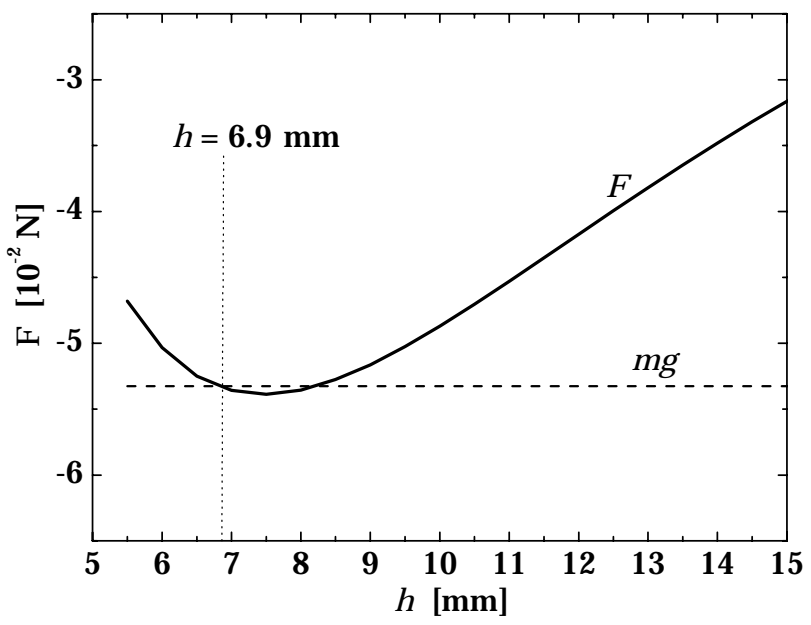

Fig. 3 Force exerted on an iron ball as a function of $h$. 
付録に示す.

浮上鉄球に作用する力を(7)式を用いて計算し，そ の結果をFig. 3 に示す。たたし，浮上鉄球も吸着鉄 球と同じものを使用していることから, 浮上鉄球の磁 化率を吸着鉄球と同じとした。同図において,引力 $\mathrm{F}$ を負の值で示しているので, $\mathrm{h}=7.5 \mathrm{~mm}$ の付近で引 力が最大となっている. $5.5 \mathrm{~g}$ の鉄球に作用する重力 $\mathrm{mg}$ を破線で示している。 $\mathrm{F}=\mathrm{mg}$ となる位置で, 鉄球 は安定して浮上するので, Fig. 3 より $\mathrm{h}=6.9 \mathrm{~mm}$ となるこ とがわかる。実験により得た結果は $7 \mathrm{~mm}$ であり, 計算結 果は測定結果と非常によく一致することがわかった。

\section{3. 浮上 鉄球の安定性}

Earnshaw の定理 ${ }^{2)}$ は, 永久磁石のような静磁界だけで 強磁性体を安定に浮上させることを禁じている。したがっ て，鉄球が浮上している位置における，磁束密度の z 成分 $\mathrm{B}_{\mathrm{z}}$ の $\mathrm{y}$ および $\mathrm{z} に よ る$ 変化を調べ, 浮上鉄球の安定性を検 討する。

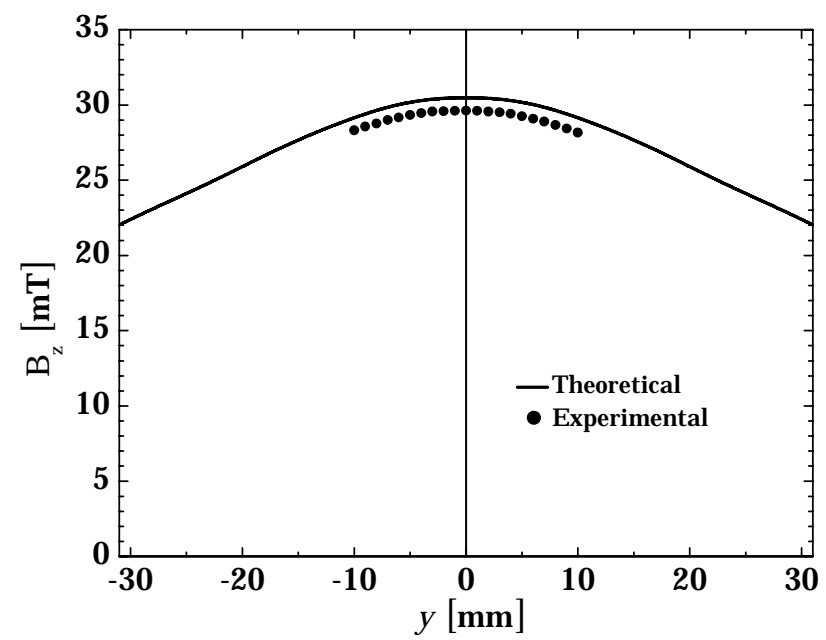

Fig. 4 Change in flux density as a function of $y$.

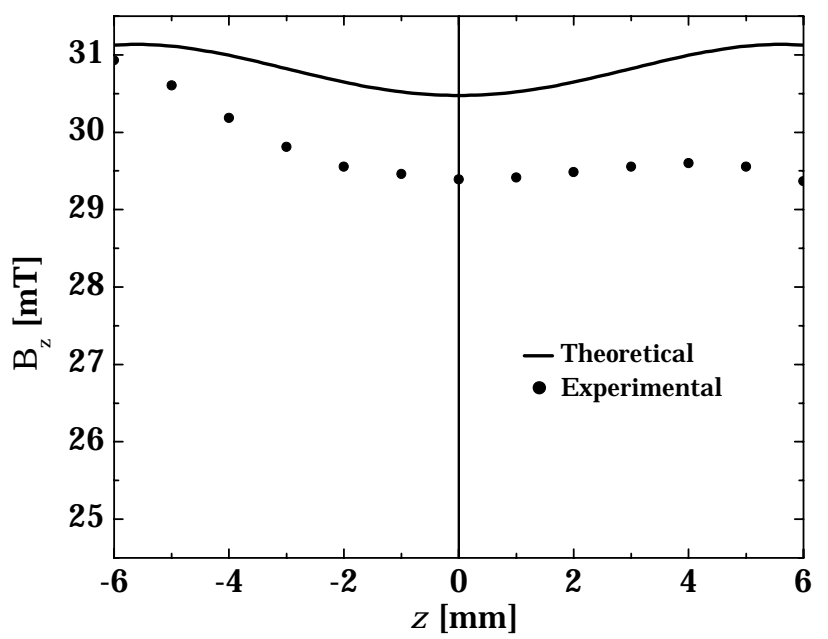

Fig. 5 Change in flux density as a function of $z$.
Fig. 3 より鉄球が浮上すると予測された位置から y 方向 に沿って変位したときの $B_{z}$ の変化を Fig. 4 に示す.Fig. 4 より $\mathrm{y}=0$ すなわち $\mathrm{x}$ 軸上で磁束密度が最大となり, 鉄球は x軸上に安定して留まることがわかる.

次に同じ位置から z 方向に沿って変位したときの磁束密 度の $z$ 成分 $B_{z}$ の変化を Fig. 5 に示す。この場合は, $x$ 軸上

（ $\mathrm{z}=0 ）$ で磁束密度は $\mathrm{z}$ 成分のみを有するが， $\mathrm{x}$ 軸から離れ ると $\mathrm{x}$ 成分は0ではなくなる。しかし, Fig. 5 から $\mathrm{B}_{\mathrm{z}}$ は $\mathrm{x}$ 軸上で最小であり， $x$ 成分も加えると磁束密度は $z$ の増大 によってさらに大きく変化する。このことから鉄球は $\mathrm{x}$ 軸 上に安定して留まることはできないことがわかる。したが って，本実験の系では Earnshawの定理が成立しているこ とが確認された。Fig. 5 において，磁界が非対称でピーク に約 4\%の差が現れており，これは吸着した鉄球の位置が $\mathrm{z}=0$ の位置からわずかにずれていることが原因と考えられ るが，磁束密度がx軸上で最小であることは明確である。

Sasaki ら ${ }^{1)}$ は浮上している鉄球がプラスチックのケー スに接触せずに安定していると主張している，また，その 理由としてプラスチックのケースが反磁性体であることか ら，その反発力の可能性を示唆している.

本研究では, Fig. 6 に示すように, x軸から zだけ変位し

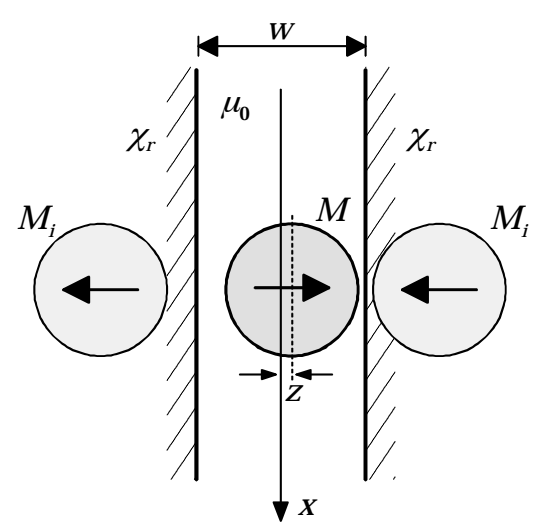

Fig. 6 An iron ball and its images.

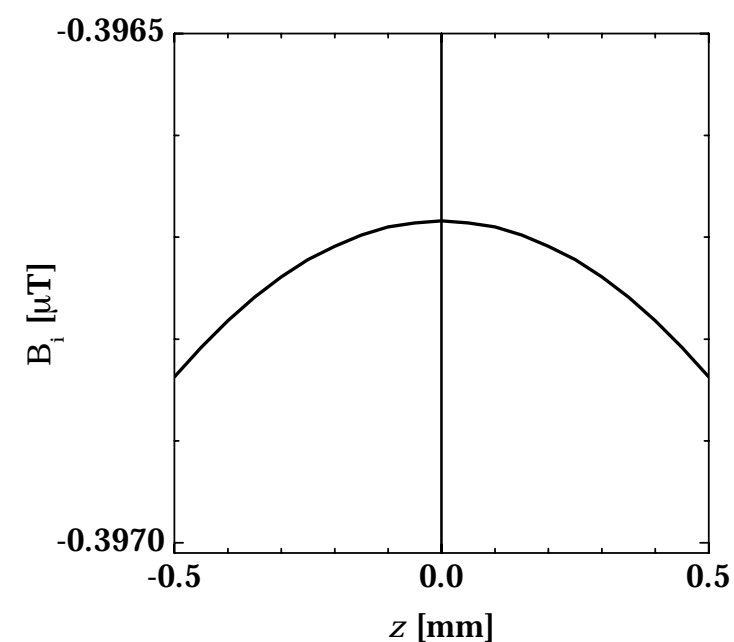

Fig. 7 Flux density due to iron ball images as a function of $z$. 
た鉄球の鏡像を考える.鉄球の磁気モーメントをM $\mathrm{M}$ とる とき, 鏡像の磁気モーメント $M_{i}$ は次式で与えられる ${ }^{4)}$.

$$
\mathrm{M}_{\mathrm{i}}=\frac{\mu_{0}-\mu}{\mu_{0}+\mu} \mathrm{M}=-\frac{\chi_{\mathrm{r}}}{2} \mathrm{M}
$$

ここで, $\mu$ および $\chi_{\mathrm{r}}$ はプラスチックケースの透磁率と比 磁化率である。 $\mu=\mu_{0}\left(1+\chi_{\mathrm{r}}\right)$, さらに $\chi_{\mathrm{r}} \ll 1$ の関係を用い た. 鏡像による鉄球の中心の位置の磁束密度は次式で表さ れる。

$$
\left.B_{i}=\left(M_{i} / 2 \pi\right)(w / 2+z)^{-3}+(w / 2-z)^{-3}\right]
$$

VSM で測定したプラスチックケースの比磁化率 $\chi_{\mathrm{r}}$ $=9.37 \times 10^{-6}$ を用いて，(8)，(9)式により計算した $\mathrm{B}_{\mathrm{i}}$ の結果 をFig. 7 に示す。同図から明らかなように，鏡像による磁 束密度は, Fig. 5 に示す磁束密度の変化に対して非常に小 さく，鉄球を $\mathrm{z}$ 方向に束縛できるものではないことがわか った．鉄球が浮上している様子を $\mathrm{y}$ 軸の方向から見た写真 をFig. 8 に示す。同図では，右側の壁と鉄球の間にも隙間 があるように見えるが，薄い紙を挿入しようとすると鉄球 が紙に触れて回転することから, 鉄球が非常に弱い力で壁 に接触していることが確認された。

\section{4. まとめ}

本研究では, リング型永久磁石と吸着している鉄球によ る磁界を理論と実験により解析し，浮上している鉄球に作 用する磁気的な力について調べた。ささらにEarnshawの定 理に関連して，浮上鉄球の安定性について調べた。その結 果, 次のことがわかった。

(1) リング型磁石による磁界, 吸着鉄球による磁界の両者 とも, 理論と実験による磁界の值は非常によく一致した. このことから, 磁界の理論曲線から力を計算することは 妥当であると考えられる.

(2) $\mathrm{x}$ 方向および $\mathrm{y}$ 方向に対しては，鉄球が安定に浮上す ることを確認した。

（3）磁界から予測された鉄球の安定して浮上する位置が, 測定した結果と非常によく一致した.

（4）しかし，浮上した鉄球は，磁界による力だけでは z 方 向には安定しないことがわかった.このことから, Sasaki らの実験および本実験は, Earnshaw の定理が禁じてい る「磁界だけによる安定浮上」ではないことがわかった。

(5) Sasaki らが示唆したような, プラスチックケースの反 磁性による反発力は非常に微小であり，この反発力によ って鉄球がケースに接触せずに安定して浮上させること は不可能であることがわかった．鉄球を $\mathrm{z}$ 方向に安定す る程度に反磁性による反発力が大きい場合は, 鏡像 $M_{i}$ の磁界によって鉄球の位置の磁界が小さくなり, Fig. 2 またはFig. 4 のような磁束密度のピークがなくなり，や はり鉄球は安定浮上できなくなる。

しかし, 本研究では鉄球とプラスチックケースの間の静

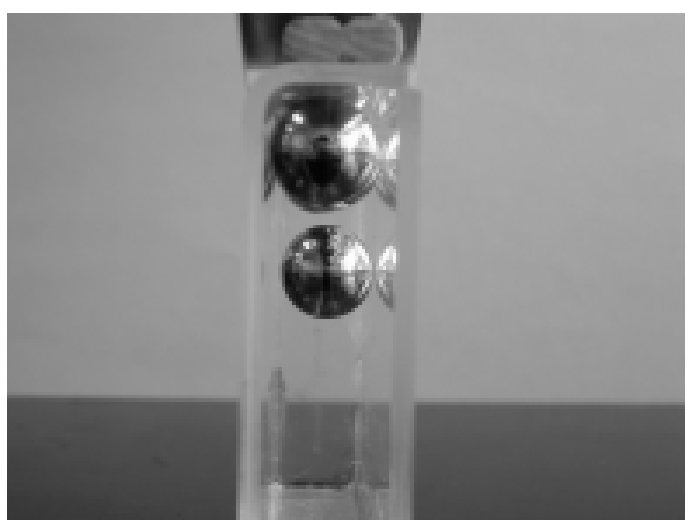

Fig. 8 An iron ball suspended in a plastic box. View along y-axis.

電力など, 磁気力以外の力については考慮していない.

\section{References}

1) S.Sasaki, I.Yagi, and M.Murakami: J .Appl.Phys., 95, 2090 (2004).

2) S.Earnshaw: Trans.Cambridge Philos.Soc., 7, 97 (1842).

3) K.Ohta: J ikikogaku no kiso, Vol. 1 (Kyoritsu Shuppan, Tokyo, 1973). (in J apanese)

4) Y.Kotsuka: Denkijikigaku, (Morikita Shuppan, Tokyo, 1998). (in J apanese)

\section{付録}

鉄球を磁界 H の中に置くとき, 鉄球の磁化」は次式で表 される。

$$
\mathrm{J}=\chi \mathrm{H}_{\mathrm{i}}
$$

ただし， $\mathrm{H}_{\mathrm{i}}$ は鉄球の内部の磁界で, 反磁界 $\mathrm{H}_{\mathrm{d}}$ と次の関係 にある。

$$
\mathrm{H}_{\mathrm{i}}=\mathrm{H}-\mathrm{H}_{\mathrm{d}}=\mathrm{H}-\mathrm{NJ} / \mu_{0} \text {. }
$$

$(A-1) ，(A-2)$ 式より， $H_{i}$ と $H$ の関係が得られる.

$$
\mathrm{H}_{\mathrm{i}}=\mathrm{H} /\left(1+\mathrm{N} \chi_{\mathrm{r}}\right) \text {. }
$$

このときの鉄球の磁気エネルギーW $\mathrm{W} 反$ 磁界エネルギーと ゼーマンエネルギーの和として，次式で与えられる。

$$
\begin{aligned}
\mathrm{W} & =\left(\mathrm{NJ}^{2} / 2 \mu_{0}\right) \mathrm{V}-\mathrm{MH}=\left\lfloor\left(\mathrm{NJ}{ }^{2} / 2 \mu_{0}\right)-J \mathrm{H}\right\rfloor \\
& =-\left(1-\frac{\mathrm{N}}{2} \frac{\chi_{\mathrm{r}}}{1+\mathrm{N} \chi_{\mathrm{r}}}\right) \frac{\mu_{0} \chi_{\mathrm{r}} \mathrm{H}^{2}}{1+\mathrm{N} \chi_{\mathrm{r}}} \mathrm{V} .
\end{aligned}
$$

(A-4) 式より，鉄球に作用する力が得られる.

$$
\begin{aligned}
\mathrm{F} & =-\frac{\partial \mathrm{W}}{\partial \mathrm{X}} \\
& =\left(1-\frac{\mathrm{N}}{2} \frac{\chi_{\mathrm{r}}}{1+\mathrm{N} \chi_{\mathrm{r}}}\right) \frac{\mu_{0} \chi_{\mathrm{r}}}{1+\mathrm{N} \chi_{\mathrm{r}}} \mathrm{V} \times 2 \mathrm{H} \frac{\partial \mathrm{H}}{\partial \mathrm{x}} .
\end{aligned}
$$

2006年9月23日受理，2007年1月23日採録 